\title{
High performance wire-shaped supercapacitive electrodes based on activated carbon fibers core/manganese dioxide shell structures
}

\author{
Shulan Jiang ${ }^{1 *}$, Siyi Cheng ${ }^{2}$, Yuanyuan Huang ${ }^{2}$, Tielin $\mathrm{Shi}^{2}$, Zirong Tang ${ }^{2}$ \\ 1.Tribology Research Institute, Key Laboratory of Advanced Technologies of Materials (Ministry \\ of Education), Southwest Jiaotong University, Chengdu 610031, China \\ 2.State Key Laboratory of Digital Manufacturing Equipment and Technology, Huazhong \\ University of Science and Technology, 1037 Luoyu Road, Wuhan 430074, China
}

\section{Key words:}

activated carbon fibers, manganese dioxide nanostructures, electrodeposition, wire-shaped electrode, supercapacitor

\begin{abstract}
Micro/nano hierarchical structures with uniformly patterned nanostructures shell and activated internal core are promising for boosting electrochemical performance. Here we report the fabrication of wire-shaped supercapacitive electrodes with manganese dioxide $\left(\mathrm{MnO}_{2}\right)$ nanostructures shell integrated onto activated carbon fiber (ACF) core. The ACF core is doped with nitrogen heteroatom and shows good conductivity and hydrophilicity, which endow fast ion and electron transport and high accessibility of electrolyte. The $\mathrm{MnO}_{2}$ nanostructures shell integrated on the ACF core by electrodeposition method together provide significant pseudocapacitive contribution associated with fast faradaic reactions. The electrochemical performance of the fabricated electrodes was evaluated by cyclic voltammetry, galvanostatic charging/discharging and electrochemical impedance spectroscopy techniques. The integrated wire-shaped electrodes, which boost the synergetic effect of $\mathrm{MnO}_{2}$ nanostructures and ACF, have excellent current collecting capabilities thus resulting high electrochemical performance (with the specific capacitance of $26.64 \mathrm{mF} \mathrm{cm}^{-1}$ at the current density of $0.1 \mathrm{~mA} \mathrm{~cm}^{-1}$ and $96 \%$ capacitance retention after 8,000 charging/discharging cycles at the current density of $1 \mathrm{~mA} \mathrm{~cm}^{-1}$ ) .
\end{abstract}




\section{Introduction}

The increasing development of miniaturized/portable electronic devices such as flexible/wearable electronics [1], roll-up displays and distributed sensors[2, 3] requires high performance, light weight and integrated energy storage/supply modules to ensure functionality [4, 5]. The wire-shaped energy storage devices have attracting attentions for the advantage of integrating with well-developed textile technology in highly versatile manner [6]. Compared with other conventional energy storage devices, supercapacitor (also called electrochemical capacitor) becomes competitive for its high power density, fast rates of charge-discharge, good cycling stability and safe operation. Electronic double layer capacitor (EDLC) and pseudocapacitor are the two main kinds of supercapacitors. The energy of EDLC is stored through ion adsorption and the accumulation of charge is purely electrostatic, while the energy of pseudocapacitor is stored through fast redox reactions between the electrolyte and active materials on the electrode surface [7]. Carbon materials such as graphene [8] and carbon nanotubes [9, 10] are typical EDLC materials, which have the advantages of large surface area, high electrical conductivity, and environmental friendliness [11]. $\mathrm{MnO}_{2}$ is one of the most promising pseudocapacitive materials for high theoretical specific capacitance, low-cost, environmental benign, etc [5, 8]. Literatures have reported that combine the advantages of both EDLC and pseudocapacitance like carbon materials and transition metal oxides or electrically conducting polymers are valuable for the capacitance enhancement of microelectrodes or devices [12-14]. For example, Tang et al. [12] have reported the fabrication of high performance on-chip microelectrodes by integration of carbon nanotubes through assembly process and electrodeposition of $\mathrm{MnO}_{2}$ thin film together to the high-aspect-ratio carbon-microelectrochemical system microelectrodes. Fibrous network nanoarchitecture with high ionic conductivity and electronic transport properties has been developed by the combination of conductive polymer fibrous polypyrrole with highly aligned large sized graphene nanosheets in a multilayered configuration, depending on the capillary force driven self-assembly coupled with the strong van der Waals attraction between highly aromatic graphene basal plane and $\pi$ conjugated conductive polymer chains [13]. Lu et al. [14] have proposed the synthesis of $\mathrm{WO}_{3-\mathrm{x}} @ \mathrm{Au} @ \mathrm{MnO}_{2}$ nanowires on carbon fabric through high-temperature thermal evaporation and growth, sputtering deposition and anodic electrodeposition processes in sequence. The synthesized electrodes show outstanding electrochemical performance such as high specific capacitance and good cyclic stability. Wire-shaped electrode with high flexibility and electrochemical property shows promising applications, so it is highly desired to fabricate high performance wire-shaped supercapacitive electrodes. Xia et al. [15] have reported the fabrication of wire-shaped supercapacitors through twisting the $\mathrm{Ni}(\mathrm{OH})_{2}$ nanowires/Ni wire electrode and ordered mesoporous carbon/ $\mathrm{Ni}$ wire electrode with a polymer electrolyte. Microfibers constructing from graphene and carbon nanotubes were also reported to fabricate wire-shaped supercapacitors [16-18]. However, the fabrication of wire-shaped high performance electrodes through activating carbon fibers core and then integrating of active materials shell onto the core is rarely reported, which is promising for boosting electrochemical performance.

Previously, we have proposed low-cost method to fabricate high performance activated carbon fiber electrodes through wet chemical treatment combined with thermal annealing process [19]. By modifying the above fabrication approach using wet chemical treatment and hydrothermal process, nitrogen-doped and activated carbon fiber electrodes were fabricated [20]. 
The activated carbon electrodes demonstrate excellent electrochemical performance due to enlarged surface area, good wettability and nitrogen heteroatoms. In this study, we have fabricated integrated electrodes with the growth of $\mathrm{MnO}_{2}$ thin film on the activated and nitrogen-doped carbon fibers, which is promising to improve the electrochemical performance of the wire-shaped electrodes. Our work is the first time that the method of activating carbon fibers has been used to fabricate wire-shaped supercapacitive electrodes. The electrode shows good electrochemical performance, with high specific capacitance (about $26.64 \mathrm{mF} \mathrm{cm}^{-1}$ at the current density of $0.1 \mathrm{~mA}$ $\mathrm{cm}^{-1}$ ) and good cyclability (96\% capacitance retention after 8,000 charging/discharging cycles at the current density of $1 \mathrm{~mA} \mathrm{~cm}^{-1}$ ).

\section{Experimental}

\subsection{Fabrication of $\mathrm{MnO}_{2}$ nanostructures shell/ACF core electrodes}

The activated carbon fiber bundles were treated by surface activation and nitrogen doping processes [20]. Briefly, the pristine carbon fibers were torn down from the carbon cloth (bought from CeTech CO., Ltd., China). They were cleaned carefully using ethanol and deionized water. After that, the fibers were immersed into the solution with $40 \mathrm{ml}$ concentrated sulfuric acid, $20 \mathrm{ml}$ concentrated nitric acid and $6 \mathrm{~g}$ potassium permanganate mixed uniformly. They were kept stirring for 3 hours at $35^{\circ} \mathrm{C}$. Then $100 \mathrm{ml}$ deionized water was added into the mixed solution and stirred for about 3 hours. Hydrogen peroxide solution was added in the above solution until no gas bubbles evolving. The samples were taken out, cleaned with deionized water and dried at room temperature. Afterwards, they were put into the Teflon lined stainless-steel autoclave containing 5 $\mathrm{ml}$ ammonium hydroxide and $70 \mathrm{ml}$ deionized water, and heated at $120^{\circ} \mathrm{C}$ for 4 hours. After cleaning with plenty of water and drying in ambient environment, the ACFs were obtained.

The $\mathrm{MnO}_{2}$ films were grown on the ACFs by electrochemical deposition method with the electrochemical workstation Autolab PGSTAT302N. The electrochemical deposition was conducted using three-electrode system, with the ACFs, the platinum plate and $\mathrm{Ag} / \mathrm{AgCl}$ as working electrode, counter electrode and reference electrode, respectively. The precursor solution was composed of $0.1 \mathrm{M}$ manganese acetate and $0.1 \mathrm{M}$ sodium sulfate [21]. During the electrodeposition process, the solution was magnetically stirring at a rotational speed of $100 \mathrm{rpm}$ [22]. The schematic diagram of electrodeposition process is shown in Figure 1.

\subsection{Characterization}

The structure and morphology of the samples were characterized by scanning electron microscopy (SEM, JEOL 7600). The oxidation state of Mn was characterized by X-ray photoelectron spectroscopy on a VG MultiLab 2000 system with a monochromatic Al Ka X-ray source (ThermoVG Scientific). The electrochemical performances of ACF core/ $\mathrm{MnO}_{2}$ nanostructures shell electrodes were tested by a three-electrode system in $1 \mathrm{M} \mathrm{Na}_{2} \mathrm{SO}_{4}$ electrolyte at room temperature. The three-electrode assembly was constructed using the fabricated sample as working electrode, the $\mathrm{Ag} / \mathrm{AgCl}$ electrode as reference electrode, and the $\mathrm{Pt}$ foil as counter electrode, respectively. The cyclic voltammetry tests were carried out using electrochemical workstation (Autolab PGSTAT302N) at the voltage range from $0 \mathrm{~V}$ to $1 \mathrm{~V}$ and at different scan rates. Galvanostatic charging/discharging tests were conducted using a battery tester (LAND-CT2001A) with the voltage window of $0 \mathrm{~V}$ to $1 \mathrm{~V}$ at various current densities. The electrochemical impedance spectroscopy (EIS) tests were carried out via Autolab PGSTAT302N 
by applying an $\mathrm{AC}$ voltage with $5 \mathrm{mV}$ amplitude in a frequency range from $0.1 \mathrm{~Hz}$ to $100 \mathrm{kHz}$ at open circuit potential.

\section{Results and discussion}

\subsection{Structural characterizations}

The activated carbon fibers and $\mathrm{MnO}_{2}$ nanostructures show micro/nano hierarchical morphology. The activated carbon fibers have high electrical conductivity and good hydrophilicity, which allows fast electron conduction and high accessibility of the electrolyte within the carbon fibers. The $\mathrm{MnO}_{2}$ thin films together with the carbon fibers are expected to improve the electrochemical performance significantly by the tailored architecture. The morphologies of the ACF core $/ \mathrm{MnO}_{2}$ shell structures were observed through SEM. As shown in Figure $2 \mathrm{a} \sim 2 \mathrm{~h}$, various morphologies of structures had been obtained through adjusting the electrodeposition parameter. Figure 2a and 2e show the morphologies of the $\mathrm{MnO}_{2}$ nanostructures/activated carbon fiber deposited for $3 \mathrm{~min}$ at different magnifications. The body of ACF core was not fully covered by $\mathrm{MnO} 2$ nanowires uniformly. When the deposition duration was prolonged (such as 6 min and 9 $\min$ ), the $\mathrm{MnO}_{2}$ nanowires began to agglomerate, with the top of the nanowires tied together (as shown in Figure 2b, 2c, 2f and 2g). When the $\mathrm{MnO}_{2}$ nanowires were electrodeposited on carbon fibers for $15 \mathrm{~min}$, they agglomerated severely and big particle islands formed, as shown in Figure $2 \mathrm{~d}$ and $2 \mathrm{~h}$. The $\mathrm{MnO}_{2}$ films exhibit dense morphologies and thus the effective surface area of the structures is reduced.

The formation of $\mathrm{MnO}_{2}$ nanostructures changes from oxidation of $\mathrm{Mn}$ (II) ions to unstable intermediate species $(\mathrm{Mn}(\mathrm{III}))$, and then $\mathrm{MnO}_{2}$ structures are chemically formed through the disproportionation reaction [23]. The Mn2p XPS spectrum of the $\mathrm{MnO}_{2}$ structures is shown in Figure 3. The two typical peaks at the binding energies of $642.1 \mathrm{eV}$ and $653.7 \mathrm{eV}$ correspond to $\mathrm{Mn} 2 \mathrm{p}_{3 / 2}$ and $\mathrm{Mn} 2 \mathrm{p}_{1 / 2}$, respectively. It is in good agreement with those reported for $\mathrm{MnO}_{2}$ and it also means that the oxide nanocrystals are $\mathrm{MnO}_{2}$, which has the oxidation state of $\mathrm{Mn}^{4+}[12,24]$. The as-fabricated $\mathrm{MnO}_{2}$ nanostructures contain water in the structures, which may enhance the transportation of active ionic species and thus improve the electrochemical performance (such as capacitance and rate capability) of manganese oxides [22].

\subsection{Electrochemical performances of the fabricated wire-shaped electrodes}

The electrochemical performances of ACF core/ $\mathrm{MnO}_{2}$ nanostructures shell electrodes were studied by cyclic voltammetry (CV) tests. The CV performances of different electrodes at the scan rate of $50 \mathrm{mV} \mathrm{s}^{-1}$ are shown in Figure 4a. For the pristine carbon fiber and activated carbon fiber, $\mathrm{CV}$ curves show a close symmetric rectangular shape and demonstrate a near mirror-image current response on voltage reversal, consequently indicating good reversibility and capacitive properties. While the $\mathrm{CV}$ curves of the electrodes with $\mathrm{MnO}_{2}$ nanostructures grown on activated carbon fibers show pseudocapacitve property as shown in Figure 4a. The voltammetric current of the activated carbon fiber electrode is greatly increased compared with that of pristine carbon electrode, which can be attributed to the enlarged surface area, improved conductivity and electrode/electrolyte wettability of the activated and nitrogen doped carbon fibers [20]. Integration of active materials such as $\mathrm{MnO}_{2}$ nanostructures onto the ACF is an effective approach to boost the electrochemical performance of carbon fibers based energy storage devices. As shown in Figure 4a, the $\mathrm{MnO}_{2}$ nanostructures shell/ACF core electrodes show better electrochemical performance than the bare activated carbon electrodes. The synergistic effect of ACF core and $\mathrm{MnO}_{2}$ film shell contributes 
together to the voltammetric current increment of the composite structure. Moreover, with the extension of electrodeposition duration, the voltammetric current increases as well. The CV curves of the wire-shaped electrode with 9 min electrodeposition of $\mathrm{MnO}_{2}$ nanostructures are shown in Figure $4 \mathrm{~b}$. The $\mathrm{CV}$ curves exhibit symmetric rectangular shape at different scan rates, and the voltammetric current of the wire-shaped electrode increases with the scan rate. When the scan rate is as high as $100 \mathrm{mV} \mathrm{s}^{-1}$, the $\mathrm{CV}$ curves still keep near rectangular shape, which indicates good electrochemical property. The capacitance of carbon fibers arises from the pure electrostatic charge accumulated at the interface of electrolytes and the charged electrodes. While the pseudo-capacitance of $\mathrm{MnO}_{2}$ structures mainly comes from the surface faradic reaction and bulk faradic reaction, which generates on the surface and in the bulk of $\mathrm{MnO}_{2}$ structures in contact with the aqueous $\mathrm{Na}_{2} \mathrm{SO}_{4}$ electrolyte $[12,25]$.

To further evaluate the electrochemical properties of the fabricated wire-shaped electrodes, the galvanostatic charging/discharging measurement was conducted. The charging/discharging curves of the electrodes are shown in Figure 5a and Figure 5b. The charging curves are relatively symmetric to the corresponding discharging curves, demonstrating good electrochemical performance. The average specific capacitance can be calculated through the charging/discharging curves according to the following equation:

$$
C=\frac{I_{A} \times \Delta t}{\Delta V \times L}
$$

where $I_{A}(\mathrm{~mA})$ is the applied current for charging/discharging measurement, $\Delta t(\mathrm{~s})$ is the discharging time. $\Delta V$ is the potential window in the discharging process, and $\mathrm{L}$ is the projected length of the wire-shaped microelectrode. As shown in Figure 4c, the length specific capacitance increases with the increment of electrodeposition time. For the wire-shaped electrode with the electrodeposition of $3 \mathrm{~min}$, the length specific capacitance is about $10.8 \mathrm{mF} \mathrm{cm}^{-1}$ at the current density of $0.1 \mathrm{~mA} \mathrm{~cm}^{-1}$. While it retains $67 \%\left(7.2 \mathrm{mF} \mathrm{cm}^{-1}\right)$ when the current density increases to 2 $\mathrm{mA} \mathrm{cm}^{-1}$. At the current density of $0.1 \mathrm{~mA} \mathrm{~cm}^{-1}$, the length specific capacitance of the wire-shaped electrode with $5 \mathrm{~min} \mathrm{MnO}_{2}$ deposition is about $18 \mathrm{mF} \mathrm{cm}^{-1}$, while that is $26.64 \mathrm{mF} \mathrm{cm}^{-1}$ for the electrode deposited for $15 \mathrm{~min}$. When the wire-shaped electrode is fabricated with prolonged deposition durations, more active materials can be integrated onto the ACF. Thus more substances actively participate in the faradic reaction and higher capacitance is obtained. However, depositing too thick $\mathrm{MnO}_{2}$ would lower the conductivity of the electrode and lead to deterioration of electrochemical performance. Consequently, we adjust the maximal electrodeposition to $15 \mathrm{~min}$ in this study. The length specific capacitance decreases gradually with the increment of current densities. For example, for the wire-shaped electrode with 9 min deposition of $\mathrm{MnO}_{2}$, the length specific capacitances are around $18 \mathrm{mF} \mathrm{cm}^{-1}, 14.76 \mathrm{mF} \mathrm{cm}^{-1}, 12.96 \mathrm{mF} \mathrm{cm}^{-1}, 11.88 \mathrm{mF} \mathrm{cm}^{-1}, 11.52$ $\mathrm{mF} \mathrm{cm}^{-1}$ and $10.44 \mathrm{mF} \mathrm{cm}^{-1}$ when the current densities are $0.1 \mathrm{~mA} \mathrm{~cm}^{-1}, 0.2 \mathrm{~mA} \mathrm{~cm}^{-1}, 0.4 \mathrm{~mA} \mathrm{~cm}^{-1}$, $0.8 \mathrm{~mA} \mathrm{~cm}^{-1}, 1 \mathrm{~mA} \mathrm{~cm}^{-1}$ and $2 \mathrm{~mA} \mathrm{~cm}^{-1}$ respectively. When the current density is low, the ions can be diffused into the available pores effectively. But the interaction between the electrode and ions is reduced when the current density is high because the effective utilization is mainly the outer surface of the electrode and there is insufficient time for the ions to approach the electrode. At the current densities of $0.1 \mathrm{~mA} \mathrm{~cm}$ and $0.2 \mathrm{~mA} \mathrm{~cm}^{-1}$, the length specific capacitances of the wire-shaped electrode with 15 min electrodeposition of $\mathrm{MnO}_{2}$ decrease from $26.64 \mathrm{mF} \mathrm{cm}^{-1}$ to $21.24 \mathrm{mF} \mathrm{cm}^{-1}$ respectively. The specific capacitances of the wire-shaped electrode with $15 \mathrm{~min}$ 
deposition of $\mathrm{MnO}_{2}$ nanostructures decrease seriously than those of the electrode deposited with less time when the current density increases from $0.1 \mathrm{~mA} \mathrm{~cm}$ to $0.2 \mathrm{~mA} \mathrm{~cm}{ }^{-1}$. For the wire-shaped electrode with 15 min deposition of $\mathrm{MnO}_{2}$, the thick and dense structures of $\mathrm{MnO}_{2}$ will depress the diffusion rate of electrolytes into the electrode.

The electrochemical impedance spectroscopy of the wire-shaped electrode was performed in the frequency range of $0.01 \mathrm{~Hz} \sim 10^{5} \mathrm{~Hz}$ at open circuit voltage. The Nyquist plot of impedance for the wire-shaped electrode with 9 min deposition of $\mathrm{MnO}_{2}$ is shown in Figure 6a. A straight line in low frequency region and a semicircle in high frequency region can be seen in the Nyquist plot. It indicates light electrochemical polarization and good capacitive behavior. The EIS data have been fitted into an equivalent circuit model as shown in the inset of Figure 6a, which consists of R1, R2, CPE1 and CPE2 four elements. The equivalent series resistance, namely R1, equals to $7.35 \Omega$. The relatively poor conductivity of $\mathrm{MnO}_{2}$ film is responsible for the large equivalent series resistance. The charge-transfer resistance (R2) is $13.8 \Omega$, which is related to the surface property of the wire-shaped electrode, and reflects the $\mathrm{Na}^{+}$insertion/adsorption property of $\mathrm{MnO}_{2}$ thin film. CPE1 and CPE2 are constant phase elements. CPE1 denotes the double layer capacitance at the electrolyte/electrode interface, while CPE2 expresses the pseudocapacitance from the ions transfer in $\mathrm{MnO}_{2}$ film $[12,26]$.

Cycling performance is important to the wire-shaped electrode. The cycling test of $\mathrm{MnO}_{2}$ nanostructures shell/ACF core electrodes was carried out at the current density of $1 \mathrm{~mA} \mathrm{~cm}^{-1}$, and the result is shown in Figure 6b. After 8,000 charging/discharging cycling tests, the capacitance retention of the wire-shaped electrode is about $96 \%$ of its initial value, demonstrating excellent long-term electrochemical stability. The result is comparable to the reported $\mathrm{MnO}_{2} /$ carbon composite structures electrodes. For example, the electrode with $\mathrm{MnO}_{2}$ nanosheets grown on nitrogen-doped hollow carbon shells shows the cycling stability of $95.2 \%$ after 5,000 cycling test at the current density of $8 \mathrm{~A} \mathrm{~g}^{-1}$ [27]. The capacitance of the mesoporous $\mathrm{MnO}_{2} /$ carbon aerogel composite electrode retains about $97 \%$ of the initial value after 1,000 cycles [28]. The hybrid graphene/ $\mathrm{MnO}_{2}$ nanostructures based electrodes show capacitance retention of around $93 \%$ after 3,000 cycles at the current density of $1 \mathrm{~mA} \mathrm{~cm}$, while the improved electrode fabricated by wrapping of graphene/ $\mathrm{MnO}_{2}$ nanostructures with conductive polymers retains $95 \%$ of the initial capacitance after 3,000 cycling tests [29]. It is noticed that the capacitance retention decreases very slow at the beginning cycling tests, while it decreases sharply to $96 \%$ of the initial value at about 5,600 cycles. The capacitance attenuation is probably caused by the mechanism difference of carbon fiber core and $\mathrm{MnO}_{2}$ nanostructures shell, and the local falling down of $\mathrm{MnO}_{2}$ nanostructures. The fabricated wire-shaped electrodes combined with $\mathrm{MnO}_{2}$ nanostructures shell and activated carbon fiber core show good electrochemical performance (such as large length specific capacitance and good cycling stability). It provides a feasible way to fabricate high performance wire-shaped electrodes and energy storage devices by integrating active materials onto activated carbon fiber structures.

\section{Conclusion}

In this study, we have reported the fabrication of high-performance wire-shaped electrodes with $\mathrm{MnO}_{2}$ nanostructures shell integrated onto ACFs. The effect of deposition time on $\mathrm{MnO}_{2}$ nanostructures was discussed, and the electrochemical performance of the wire-shaped electrodes was evaluated through cyclic voltammetry, galvanostatic charging/discharging test, and 
electrochemical impedance spectroscopy. The ACF core together with the $\mathrm{MnO}_{2}$ nanostructures shell contribute to the high specific capacitances (about $26.64 \mathrm{mF} \mathrm{cm}^{-1}$ at the current density of 0.1 $\mathrm{mA} \mathrm{cm}{ }^{-1}$ ) and good cycling stability (96\% capacitance retention after 8,000 charging/discharging cycles at the current density of $1 \mathrm{~mA} \mathrm{~cm}{ }^{-1}$ ). The fabricated $\mathrm{ACF}$ core/ $\mathrm{MnO}_{2}$ nanostructures shell electrodes have great potential in wire-shaped miniature devices.

\section{Acknowledgement}

This work was supported by National Science Foundation of China (No. 51605400), and the Fundamental Research Funds for the Central Universities (2682016CX027). 


\section{Reference}

[1] B.D. Gates, Flexible electronics, Science. 323 (2009) 1566-1567.

[2] T. Someya, Y. Kato, T. Sekitani, S. Iba, Y. Noguchi, Y. Murase, H. Kawaguchi, T. Sakurai, Conformable, flexible, large-area networks of pressure and thermal sensors with organic transistor active matrixes, Proc. Natl. Acad. Sci. U. S. A. 102 (2005) 12321-12325.

[3] D.J. Lipomi, M. Vosgueritchian, B.C. Tee, S.L. Hellstrom, J.A. Lee, C.H. Fox, Z. Bao, Skin-like pressure and strain sensors based on transparent elastic films of carbon nanotubes, Nat. Nanotechnol. 6 (2011) 788-792.

[4] X. Wang, A. Sumboja, W.L. Foo, C.Y. Yan, K. Tsukagoshi, P.S. Lee, Rational design of a high performance all solid state flexible micro-supercapacitor on paper, RSC Adv. 3 (2013) 15827-15833.

[5] M. Kuang, W. Zhang, X.L. Guo, L. Yu, Y.X. Zhang, Template-free and large-scale synthesis of hierarchical dandelion-like $\mathrm{NiCo}_{2} \mathrm{O}_{4}$ microspheres for high-performance supercapacitors, Ceram. Int. 40 (2014) 10005-10011.

[6] P. Xu, B. Wei, Z. Cao, J. Zheng, K. Gong, F. Li, J. Yu, Q. Li, W. Lu, J. H. Byun, B. S. Kim, Y. Yan, T. W Chou, Stretchable wire-shaped asymmetric supercapacitors based on pristine and $\mathrm{MnO}_{2}$ coated carbon nanotube fibers, ACS nano. 9 (2015) 6088-6096.

[7] S. Bose, T. Kuila, A.K. Mishra, R. Rajasekar, N.H. Kim, J.H. Lee, Carbon-based nanostructured materials and their composites as supercapacitor electrodes, J. Mater. Chem. 22 (2012) 767-784.

[8] L. Wang, H. Ji, S. Wang, L. Kong, X. Jiang, G. Yang, Preparation of $\mathrm{Fe}_{3} \mathrm{O}_{4}$ with high specific surface area and improved capacitance as a supercapacitor, Nanoscale. 5 (2013) 3793-3799.

[9] G. Yu, L. Hu, M. Vosgueritchian, H. Wang, X. Xie, J.R. McDonough, X. Cui, Y. Cui, Z. Bao, Solution-processed graphene/ $\mathrm{MnO}_{2}$ nanostructured textiles for high-performance electrochemical capacitors, Nano Lett. 11 (2011) 2905-2911.

[10] E. Frackowiak, K. Metenier, V. Bertagna, F. Beguin, Supercapacitor electrodes from multiwalled carbon nanotubes, Appl. Phys. Lett. 77 (2000) 2421.

[11] F.Y. Ban, S. Jayabal, H.N. Lim, H.W. Lee, N.M. Huang, Synthesis of nitrogen-doped reduced graphene oxide-multiwalled carbon nanotube composite on nickel foam as electrode for high-performance supercapacitor, Ceram. Int. 43 (2017) 20-27.

[12] E. Frackowiak, F. Beguin, Carbon materials for the electrochemical storage of energy in capacitors, Carbon. 39 (2001) 937-950. 
[13] S. Jiang, T. Shi, D. Liu, H. Long, S. Xi, F. Wu, X. Li, Q. Xia, Z. Tang, Integration of $\mathrm{MnO}_{2}$ thin film and carbon nanotubes to three-dimensional carbon microelectrodes for electrochemical microcapacitors, J. Power Sources. 262 (2014) 494-500.

[14] S. Biswas, L.T. Drzal, Multilayered nanoarchitecture of graphene nanosheets and polypyrrole nanowires for high performance supercapacitor electrodes, Chem. Mat. 22 (2010) 5667-5671.

[15] X. Lu, T. Zhai, X. Zhang, Y. Shen, L. Yuan, B. Hu, L. Gong, J. Chen, Y. Gao, J. Zhou, $\mathrm{WO}_{3-\mathrm{x}} @ \mathrm{Au} @ \mathrm{MnO}_{2}$ core-shell nanowires on carbon fabric for high-performance flexible supercapacitors, Adv. Mater. 24 (2012) 938-944.

[16] X. Dong, Z. Guo, Y. Song, M. Hou, J. Wang, Y. Wang, Y. Xia, Flexible and wire-shaped micro-supercapacitor based on $\mathrm{Ni}(\mathrm{OH})_{2}$-nanowire and ordered mesoporous carbon electrodes, Adv. Funct. Mater. 24 (2014) 3405-3412.

[17] Y. Meng, Y. Zhao, C. Hu, H. Cheng, Y. Hu, Z. Zhang, G. Shi, L. Qu, All-graphene core-sheath microfibers for all-solid-state, stretchable fibriform supercapacitors and wearable electronic textiles, Adv. Mater. 25 (2013) 2326-2331.

[18] H. Sun, X. You, J. Deng, X. Chen, Z. Yang, J. Ren, H. Peng, Novel graphene/carbon nanotube composite fibers for efficient wire-shaped miniature energy devices, Adv. Mater. 26 (2014) 2868-2873. [19] P. Xu, T. Gu, Z. Cao, B. Wei, J. Yu, F. Li, J.H. Byun, W. Lu, Q. Li, T. W. Chou, Carbon nanotube fiber based stretchable wire-shaped supercapacitors, Adv. Energy Mater. 4 (2014) 1300759.

[20] S. Jiang, T. Shi, X. Zhan, H. Long, S. Xi, H. Hu, Z. Tang, High-performance all-solid-state flexible supercapacitors based on two-step activated carbon cloth, J. Power Sources. 272 (2014) 16-23.

[21] S. Jiang, X. Zhan, Y. Huang, Z. Tang, Superior electrochemical performance of carbon cloth electrode-based supercapacitors through surface activation and nitrogen doping, Ionics. 22 (2016) 1881-1890.

[22] D. Tench, L.F. Warren, Electrodeposition of conducting transition metal oxide/hydroxide films from aqueous solution, J. Electrochem. Soc. 130 (1983) 869-872.

[23] M. S. Wu, Z. S. Guo, J. J. Jow, Highly regulated electrodeposition of needle-like manganese oxide nanofibers on carbon fiber fabric for electrochemical capacitors, J. Phys. Chem. C. 114 (2010) 21861.

[24] G.H.A. Therese, P.V. Kamath, Electrochemical synthesis of metal oxides and hydroxides, Chem. Mat. 12 (2000) 1195-1204.

[25] H. Xia, J. Feng, H. Wang, M.O. Lai, L. Lu, Fabrication of graphene oxide/polypyrrole nanowire 
composite for high performance supercapacitor electrodes, J. Power Sources. 195 (2010) 4410-4413.

[26] M. Toupin, T. Brousse, D. Bélanger, Charge storage mechanism of $\mathrm{MnO}_{2}$ electrode used in aqueous electrochemical capacitor, Chem. Mat. 16 (2004) 3184-3190.

[27] W. Sun, R. Zheng, X. Chen, Symmetric redox supercapacitor based on micro-fabrication with three-dimensional polypyrrole electrodes, J. Power Sources. 195 (2010) 7120-7125.

[28] L. Li, R. Li, S. Gai, S. Ding, F. He, M. Zhang, P. Yang, $\mathrm{MnO}_{2}$ nanosheets grown on nitrogen-doped hollow carbon shells as a high-performance electrode for asymmetric supercapacitors, Chem.-Eur. J. 21 (2015) 7119-7126.

[29] G.-R. Li, Z.-P. Feng, Y.-N. Ou, D. Wu, R. Fu, Y. X. Tong, Mesoporous $\mathrm{MnO}_{2} /$ carbon aerogel composites as promising electrode materials for high-performance supercapacitors, Langmuir. 26 (2010) 2209-2213.

[30] G. Yu, L. Hu, N. Liu, H. Wang, M. Vosgueritchian, Y. Yang, Y. Cui, Z. Bao, Enhancing the supercapacitor performance of graphene/ $\mathrm{MnO}_{2}$ nanostructured electrodes by conductive wrapping, Nano Lett. 11 (2011) 4438-4442. 


\section{Figure captions}

Figure 1. The schematic diagram of fabricating ACF core/ $\mathrm{MnO}_{2}$ nanostructures shell electrodes.

The inset is the photograph of the fabricated fiber structures.

Figure 2. SEM images of ACF core/ $\mathrm{MnO}_{2}$ nanostructures shell with different deposition durations and magnifications. (a,e) 3min. (b,f) 6 min. (c,g) 9min. (d,h) 15min.

Figure 3. Mn2p XPS spectrum of $\mathrm{MnO}_{2}$ structures.

Figure 4. (a) $\mathrm{CV}$ curves of $\mathrm{ACF}$ core $/ \mathrm{MnO}_{2}$ nanostructures shell electrodes with different deposition time at the scan rate of $50 \mathrm{mV} \mathrm{s}^{-1}$ in $1 \mathrm{M} \mathrm{Na}_{2} \mathrm{SO}_{4}$ electrolyte. (b) $\mathrm{CV}$ curves of the wire-shaped electrode with the electrodeposition time of 9 min at various scan rates.

Figure 5. (a) Typical galvanostatic charging/discharging curves of the wire-shaped electrodes with different electrodeposition time at the current density of $0.1 \mathrm{~mA} \mathrm{~cm}^{-1}$ between $0 \mathrm{~V}$ to $1 \mathrm{~V}$. (b) Galvanostatic charging/discharging curves of the wire-shaped electrode deposited of $\mathrm{MnO}_{2}$ nanostructures with 9 min at different current densities. (c) The length specific capacitances of the wire-shaped electrodes with different $\mathrm{MnO}_{2}$ deposition durations at various current densities.

Figure 6. (a) Nyquist plot of the wire-shaped electrode with 9 min deposition of $\mathrm{MnO}_{2}$ from 0.01 $\mathrm{Hz}$ to $10^{5} \mathrm{~Hz}$. Z' is the real impedance and Z" is the imaginary impedance. The inset is the fitted equivalent circuit model. (b) The cycling performance of the hybrid wire-shaped electrode with deposition of 9 min after 8,000 charging/discharging tests. 


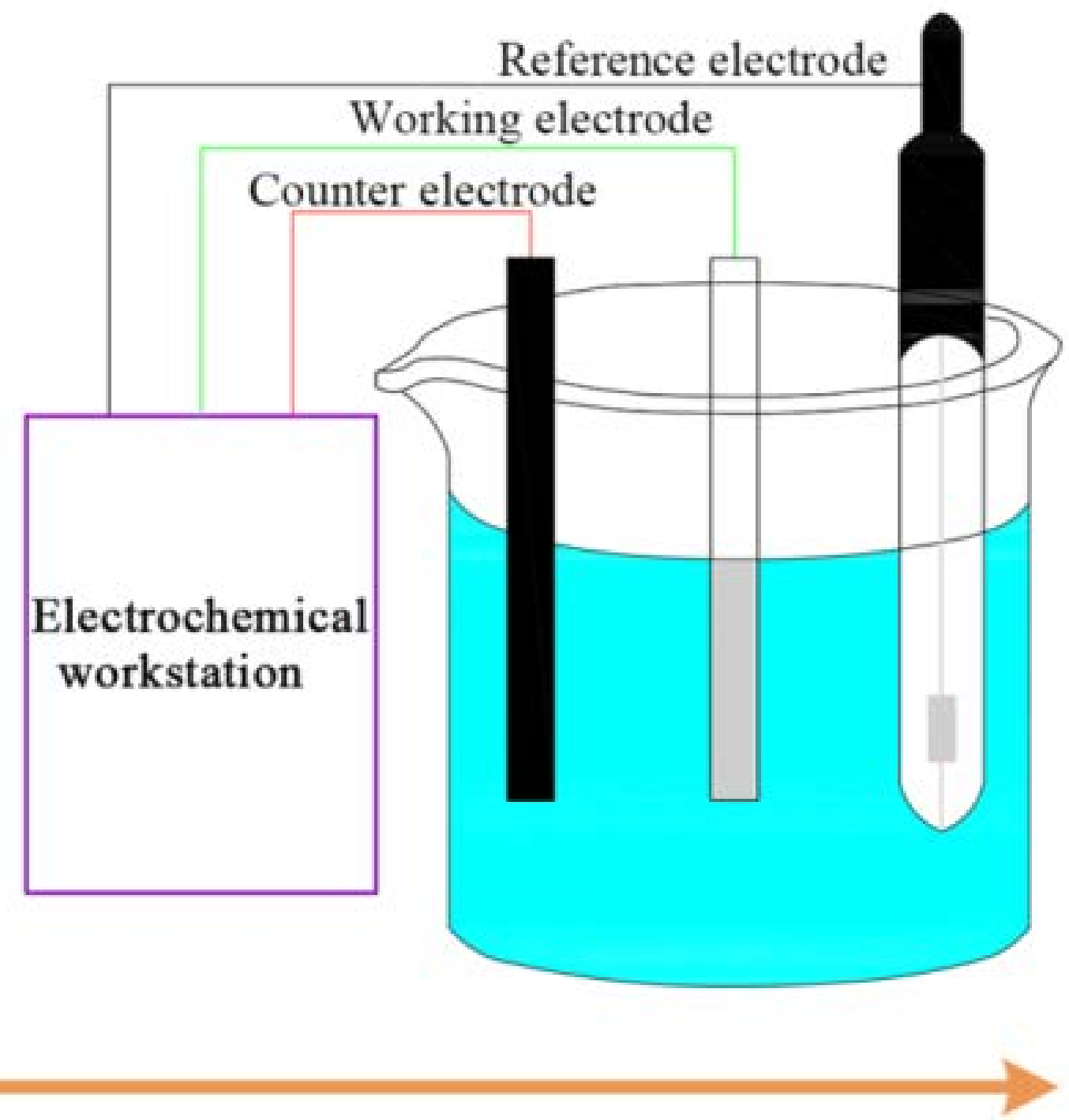




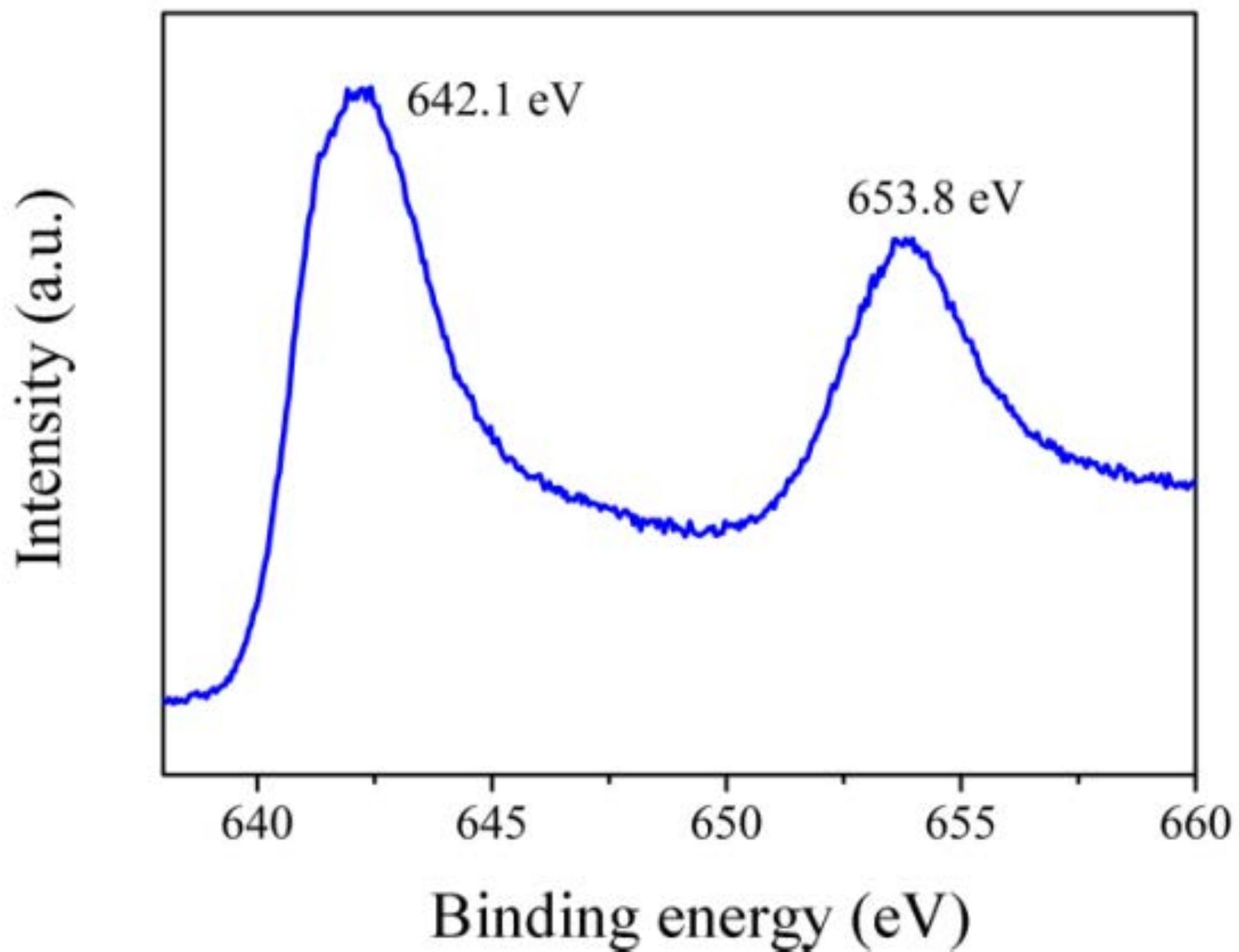




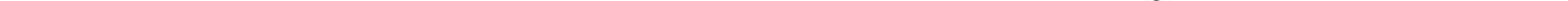

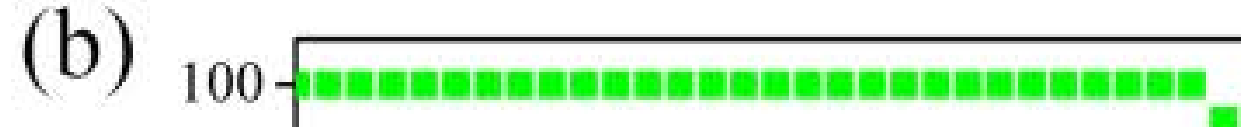

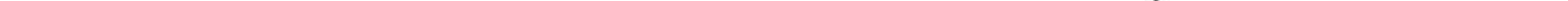

Cycle number

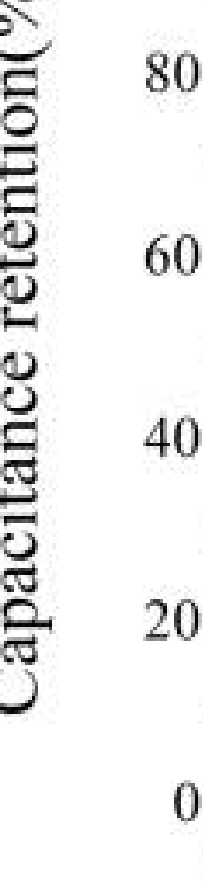

.
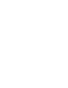